Finisterra, XXXVII, 74, 2002, pp. 193-198

\title{
COLÓQUIO PAISAGEM
}

\author{
CATARINA RAMOS \\ Mário VALE \\ LUÍS MORENO \\ José Manuel Simões
}

No dia 22 de Março de 2002, realizou-se, no Anfiteatro III da Faculdade de Letras da Universidade de Lisboa, o Colóquio Paisagem organizado pela Finisterra - Revista Portuguesa de Geografia, com o apoio do Centro de Estudos Geográficos, da Faculdade de Letras de Lisboa, da Fundação da Universidade de Lisboa e do Instituto Português do Livro e das Bibliotecas.

O Colóquio foi organizado no âmbito das comemorações dos 35 anos da revista e da publicação de um número temático sobre «Paisagem» (vol. XXXVI, n. ${ }^{\circ}$ 72). Tanto naquele número da revista, como no Colóquio, tivemos o privilégio de contar com a colaboração de dois dos seus fundadores, Suzanne Daveau e Ilídio do Amaral, e não faltaram ocasiões para relembrar Orlando Ribeiro, a quem o tema era muito grato.

Na sessão de abertura, participaram o Professor David Ferreira, Vice-Reitor da Universidade de Lisboa, e os Presidentes dos Conselhos Científico e Directivo da Faculdade de Letras da Universidade de Lisboa, respectivamente Professores João Flor e Fernanda Gil Costa. O Colóquio foi estruturado em quatro painéis, em que especialistas de diferentes formações, cedendo ao desafio lançado pela Finisterra, se debruçaram sobre o conceito de paisagem, confrontando definições e sensibilidades. No fim de cada painel, a discussão generalizou-se a muitos dos participantes no encontro (cerca de 150, provenientes de universidades e de outras instituições públicas e privadas).

No intervalo entre os painéis 3 e 4, actuou o Coro da Universidade de Lisboa, sob a direcção do Maestro José Robert. Fazendo alusão às 'Paisagens Musicais', o Coro interpretou Três Cantos Nativos do Índios Kraó (de Marcos Leite), Quo Pinus (de Svend Shultz), Ó Serpa! (de Eurico Carrapatoso) e Senhora Santa Cat'rina (de Fernando Lopes-Graça). Para lembrar que ao estudo geográfico da paisagem se pode juntar a dimensão musical.

Quatro colegas do Centro de Estudos Geográficos actuaram como relatores e redigiram as notas que se seguem, a que apenas se tentou dar alguma unidade.

Margarida Queirós Maria João Alcoforado 
O primeiro Painel (Existem Paisagens Naturais?), moderado por António de Brum Ferreira do Centro de Estudos Geográficos (CEG) da Universidade de Lisboa, contou com a participação de Teresa Pinto Correia, do Departamento de Planeamento Biofísico e Paisagístico da Universidade de Évora, Maria Lúcia Lepecki e Viriato Soromenho-Marques, respectivamente dos Departamentos de Literaturas Românicas e de Filosofia, ambos da Faculdade de Letras da Universidade de Lisboa.

António de Brum Ferreira abriu a sessão, salientando as diversas concepções de paisagem: visível, perceptível, fundamental e integral. Apresentou o seu ponto de vista, associando a paisagem a um geossistema, constituído por componentes interdependentes, pertencentes à atmosfera, litosfera, hidrosfera e biosfera (na qual se inclui o Homem). Para A. de Brum Ferreira já não existem paisagens exclusivamente naturais, mesmo em áreas inóspitas como o Árctico e a Antárctida. A acção humana intervém à escala da paisagem global (a do Planeta), por exemplo como catalisadora do efeito de estufa, mas o Planeta, como sistema global que é, tem os seus mecanismos próprios de (re)equilíbrio.

Teresa Pinto Correia destacou a complexidade do conceito de paisagem, em parte por esta ser uma realidade multifacetada. A paisagem é um sistema complexo e dinâmico composto por elementos naturais e culturais, que evoluem e interagem ao longo do tempo. Teresa P. Correia deu como exemplo a divisão de Portugal em unidades de paisagem - recordando os conceitos e metodologia utilizados num estudo que o Departamento de Planeamento Biofísico e Paisagístico da sua Universidade realizou.

Maria Lúcia Lepecki, considerando a paisagem como construção (resultando de um exercício de inteligência e de discriminação) e como diferente de natureza, que é a «matéria prima» a partir da qual se constrói, trabalhou sobre questões de linguagem verbal e de teoria do conhecimento. Começou ponderando a etimologia dos termos paisagem e natureza, a partir daí tentando mostrar que processos permitem a circunscrição do paisagístico no mundo natural: determinação e denominação de objectos, correlação entre os últimos, de modo que o delimitado se torne coerente e coeso (a paisagem é uma sintaxe, criada por selecção entre os elementos do mundo natural). Desde que coesos e coerentes, os elementos seleccionados permitem que a paisagem adquira sentido, um sentido «em si», mas só susceptível de ser apreendido se se tiver em atenção a sua relação de alteridade-complementaridade com o espaço natural de que foi destacada.

Viriato Soromenho-Marques começou por afirmar que a paisagem é uma entidade dinâmica: «a paisagem é uma metáfora das relações entre cultura e natureza». Para Soromenho-Marques, a meditação sobre a paisagem é inseparável do processo de constituição do sistema de valores, saberes e instituições. Por outras palavras, ao longo do tempo, o Homem deixou de considerar a natureza como uma ameaça, utilizando todas as suas capacidades técnico-científicas para a modificar. Em sua opinião, mesmo quando se criam «áreas naturais protegidas», a paisagem é humanizada, já que «na paisagem que protegemos, já 
lá estamos». Destacando opiniões, como a de Ribeiro Telles, discutiu a necessidade de construir as paisagens («re-naturalizando-as»), no respeito pelos princípios da sustentabilidade e biodiversidade.

O Colóquio prosseguiu com o segundo Painel (Paisagens Urbanas). Esta sessão foi conduzida por Teresa Barata Salgueiro, do CEG, e contou com a participação de Maria da Graça Saraiva, do Instituto Superior de Agronomia da Universidade Técnica de Lisboa, Pedro George, da Faculdade de Arquitectura da Universidade Técnica de Lisboa, e de Teresa Alves, do CEG.

Teresa Barata Salgueiro iniciou a sessão com uma reflexão sobre a paisagem enquanto descoberta da pintura dos finais do século XV, integrando-a numa série de eventos que estão na origem da modernidade. Desde a estética naturalista, a paisagem ocupa o pensamento dos geógrafos. A geografia do século XIX associa a paisagem ao lugar. Mais recentemente, a geografia física tem privilegiado os estudos da paisagem enquanto geossistema, ao passo que, em geografia humana, se tem procurado reflectir sobre as marcas culturais da sociedade na paisagem - crenças, práticas e tecnologias. Teresa Barata Salgueiro referiu-se mais pormenorizadamente à paisagem urbana, resultado da recente e rápida expansão da cidade e da inovação tecnológica.

Teresa Alves iniciou a sua intervenção abordando a perspectiva da geografia humana, já que entende ser a paisagem «um dos elementos centrais do sistema cultural». Tendo analisado as origens da noção de paisagem e as diversas valorizações de que foi alvo, terminou com uma reflexão acerca das paisagens críticas, que Sebastião Salgado imortalizou através dos seus Trabalho e Exodos.

Partindo do que define como paisagem urbana, rural e rurbana, em resultado da interacção conflituosa homem/natureza - o vector estruturante da paisagem, Pedro George fez uma reflexão crítica sobre a evolução da paisagem portuguesa e questionou o seu futuro. Abordou a experiência do planeamento referindo-se, em particular, à influência dos planos de ocupação do solo, da competência dos municípios, na configuração da paisagem portuguesa.

Após a apresentação da evolução do conceito de paisagem, sobretudo na perspectiva dos arquitectos paisagistas, Maria da Graça Saraiva desenvolveu a perspectiva da multidimensionalidade da paisagem urbana. Tendo salientado as complexas interacções entre as suas componentes biofísica, social, cultural e emocional, referiu-se à dificuldade da transposição das intenções dos planos de ordenamento para a intervenção na paisagem e reflectiu sobre a necessidade de desenvolver perspectivas não unicamente balizadas por critérios técnico-científicos, mas também por factores de natureza cultural e estética.

O terceiro Painel (Paisagem: inovação e tradição), moderado por Carlos Alberto Medeiros do CEG, contou com os conferencistas convidados Joaquim Romero de Magalhães, da Comissão Nacional para as Comemorações dos Descobrimentos Portugueses, Nicole Devy-Vareta, do Departamento de Geografia da Universidade do Porto, e Suzanne Daveau e Denise de Brum Ferreira, do CEG. 
Carlos Alberto Medeiros teceu algumas considerações sobre a importância da paisagem na tradição da escola geográfica francesa. Em estudos que nela se enquadram foi analisada precocemente a complexidade do conceito, embora privilegiasse na paisagem os seus elementos de carácter permanente. Foi assim introduzida a intervenção do historiador Romero de Magalhães. Influenciado pelas matérias da ciência geográfica, recordou o seu percurso escolar e académico: se, no liceu, sentiu a influência de José de Neves Júnior - também professor de Orlando Ribeiro, na Universidade de Coimbra, como aluno de José Manuel Pereira de Oliveira, efectuou inúmeras leituras de obras de geógrafos. Para além destas primeiras influências em matérias que colocavam a paisagem como alvo de atenção privilegiada, Romero de Magalhães mostrou alguns contributos do conhecimento da paisagem geográfica para uma determinada compreensão da História, sem negar a importância da relação recíproca. Salientou a relevância da documentação histórica sobre a paisagem, referindo as obras de Gaspar Barreiros, João de Barros, Frei João de São José, Gaspar Frutuoso, Duarte Nunes de Leão e Frei Bernardo de Brito.

A intervenção de Suzanne Daveau foi marcada por várias considerações sobre a dificuldade de fazer geografia sem considerar a paisagem. Recorreu a um exemplo de excepção - para confirmar a regra - relativo ao estudo do artesanato na cidade de Lisboa. Em contraponto, referiu variados exemplos de trabalhos que implicaram a consideração da paisagem, a qual «incorpora elementos de temporalidade diferente». Entre os casos ilustrativos portugueses, mencionou o litoral da Estremadura, as novas vias - auto-estradas, em particular - cuja construção destruiu marcas paisagísticas muito instrutivas e a cidade de Lisboa, cuja herança cultural explica grande parte de uma certa «disfuncionalidade» actual (ruas estreitas, por exemplo).

Nicole Devy-Vareta deu, em primeiro lugar, uma perspectiva do seu percurso académico, em que o estudo da floresta a levou a interessar-se pela paisagem, sobretudo no que respeita a uma geografia da florestação e à história da floresta em Portugal. Considerou a necessidade de abordar a questão sob duas perspectivas: a tradição e a inovação no conceito de paisagem e a "paisagem integral», que tenta fazer a conexão entre as componentes materiais e o mundo fluido da percepção. Sobre a primeira, apontou a evolução diferenciada das representações das paisagens florestais em função das diferentes «imagens» socialmente construídas sobre a floresta. Quanto à concepção de «paisagem integral», tem procurado utilizá-la como alternativa às de paisagem «rural» ou «urbana» que, na actualidade, face à crescente articulação das respectivas culturas e representações, introduzem fortes ambiguidades nas políticas de protecção paisagística.

Denise de Brum Ferreira ilustrou a dinâmica e incidências ambientais da evolução da paisagem de montado no Alentejo interior ao longo do século XX. Caracterizou a complementaridade de usos agro-silvo-pastoris característicos do montado; fez uma síntese do contexto sócio-económico e político da sua transformação, associada à intensificação do uso do solo, descontínua no tempo 
e no espaço. Entre as consequências paisagísticas apontadas, foram destacadas a diminuição do estrato arbóreo e a invasão de espécies heliófilas, mais adaptadas às novas condições. Para além das frequentes paisagens "de erosão" ou «de risco de erosão» perspectivam-se outras, em função de novas oportunidades de uso, por influências conjugadas de medidas da Política Agrícola Comum, de procuras urbanas e dos presumíveis efeitos da Barragem do Alqueva.

O quarto Painel (Outras Paisagens) foi conduzido por Jorge Gaspar, então Director do CEG, e foram oradores convidados o galerista Luís Serpa, o pintor Pedro Calapez e o arquitecto Manuel Vicente, professor no Instituto Superior Técnico.

Jorge Gaspar iniciou este painel referindo-se «ao sentir o lugar ou as paisagens da memória». Salientou que, através de um processo de selecção da informação, a memória é um modelador da paisagem, justificando esta ideia a partir da noção de paisagem de Vidal de La Blache. Recorrendo a uma sequência de imagens, Jorge Gaspar fez-nos "sentir o lugar», com uma breve incursão a partir da Faculdade de Letras de Lisboa até ao Campo Grande, regressando novamente ao mesmo local, demonstrando como através dos sentidos, «das paisagens da memória», é possível recordar a variabilidade do território no tempo.

Luís Serpa, na qualidade de organizador de exposições, recordou ser a paisagem um tema muito recorrente no seu trabalho. Começou por abordar a cidade sob o olhar d' "A cidade e as estrelas» - título que deu nome a uma iniciativa da sua galeria de arte. A síntese que traçou sobre o tema da paisagem, iniciou-se com a evolução da cidade, a partir da revolução industrial e encaminhou-se para a sua própria vivência da cidade actual.

Foi nesta perspectiva que Jorge Gaspar chamou a atenção para as «paisagens do espírito e do interior» introduzindo, assim, a intervenção de Pedro Calapez. O pintor destacou as relações entre o seu espaço interior e a paisagem exterior, salientando o seu gosto pela paisagem - que recorrentemente tem procurado retratar através das suas cores. Tal como uma máquina fotográfica, o seu trabalho tem explorado as distâncias (perto/longe) bem como as potencialidades do zoom (focado/desfocado). Por fim, optou por substituir as palavras por um vídeo da sua autoria, que intitulou Distância, procurando nele destacar as várias formas de olhar aquilo que, à margem da sua pintura, é possível observar no seu atelier, pano de fundo da realização do vídeo.

$\mathrm{O}$ arquitecto Manuel Vicente referiu a dificuldade em estabelecer a diferença entre «natural»/«artificial»e salientou o seu fascínio pela transformação. Em sua opinião, o mundo tem nexos para além dos visíveis e existe no caos uma ordem por reconhecer. Neste contexto, o mundo apresenta todas as significações possíveis. A movimentação na paisagem permite ver o que está parado; tal como a câmara do realizador de cinema, pode-se sempre voltar atrás e observar tudo de outro ângulo. A este propósito, o Arquitecto relatou uma experiência vivida de percepção da paisagem, ao efectuar uma viagem de comboio de Filadélfia para Nova Iorque, todavia sentado na direcção oposta à deslocação do 
veículo. Por fim, o seu pensamento deambulou pelas paisagens urbanas dos EUA e, tal como Jorge Gaspar, reconheceu que o mundo Disney replica a «cidade prometida».

A fechar a sessão, e também o Colóquio, Jorge Gaspar concluiu que se abrem múltiplas pistas para um novo envolvimento dos geógrafos com a paisagem: a questão-chave do nomadismo; as paisagens construídas no feminino; a distância e a escala na abordagem da paisagem; a pintura e a poesia como as melhores intérpretes das paisagens. 